\title{
Remote Sensing of Biologically Reworked Sediments: A Laboratory Experiment
}

\author{
Annelies De Backer • Stefanie Adam • Jaak Monbaliu • \\ Erik Toorman • Magda Vincx • Steven Degraer
}

Received: 15 January 2009 /Revised: 1 May 2009 / Accepted: 10 July 2009

(C) Coastal and Estuarine Research Federation 2009

\begin{abstract}
The present study aims to test the application of remote sensing to address the impact of bioturbation on physical sediment properties. Therefore, a laboratory experiment was developed, using microcosms mimicking a marine intertidal water-sediment interface to test the influence of Corophium volutator densities on sediment properties. Three main variables (water content, clay content, and mean grain size) were measured in three treatments (no Corophium, 5,000 Corophium per square meter, and 20,000 Corophium per square meter) after 16 days of bioturbation. Results obtained with conventional-destructive-techniques showed a significant increase of water content and a significant, but small decrease of clay content in the presence
\end{abstract}

A. De Backer $(\triangle) \cdot$ M. Vincx $\cdot$ S. Degraer

Marine Biology, Biology Department, Ghent University,

Campus Sterre, Krijgslaan 281-S8,

9000 Ghent, Belgium

e-mail: annelies.debacker@ilvo.vlaanderen.be

S. Adam $\cdot$ J. Monbaliu $\cdot$ E. Toorman

Hydraulics Laboratory, Department of Civil Engineering,

Katholieke Universiteit Leuven,

Kasteelpark Arenberg 40,

3001 Heverlee, Belgium

\section{S. Degraer}

Marine Ecosystem Management Section, Management Unit of the

North Sea Mathematical Model, Royal Belgian Institute of

Natural Sciences,

Gulledelle 100,

1200 Brussels, Belgium

Present Address:

A. De Backer

Animal Sciences, Fisheries, Institute for Agricultural and Fisheries

Research,

Ankerstraat 1,

8400 Oostende, Belgium of Corophium. The remote sensing technique detected the impact of Corophium on water content as an increase in absorption at $1,450 \mathrm{~nm}$, but was not able to detect the animal impact on clay content. This study demonstrates that remote sensing data could be significantly modified by bioturbation activities and that remote sensing can be applied in the laboratory to address the impact of bioturbation on sediment properties. This possibly opens new perspectives for longterm experiments concerning the role of bioturbation on sedimentary processes.

Keywords Clay content · Remote sensing · Grain size · Water content $\cdot$ Corophium volutator $\cdot$ Hyperspectral measurements

\section{Introduction}

Dependent on the surface materials, various fractions of electromagnetic radiation incident on the surface are reflected, absorbed, and/or emitted (Lillesand and Kiefer 2000). Some materials, such as the pigment chlorophyll $a$, water, and clay absorb light at specific wavelengths due to molecular vibration and rotation, while other materials, such as vegetation, scatter near-infrared light due to the internal structure of plant leaves (Lillesand and Kiefer 2000). Remote sensing devices capture the reflected radiation which can be used to identify and quantify surface materials. With the development of high spectral resolution laboratory, field, and airborne sensors, the reflected signal can be used to predict surface properties qualitatively (Thomson et al. 1998; Adam et al. 2006; Deronde et al. 2006) and, to some extent, quantitatively (Rainey et al. 2003; Carrère 2003). Remote sensing has the great advantage that it is a nondestructive method and less time consuming than conventional sampling. 
In laboratory conditions, hyperspectral signals have been used to quantify mud (Kooistra et al. 2003; Lagacherie et al. 2008; Adam 2009), organic matter (Ben-dor et al. 2002; Kooistra et al. 2003), chlorophyll $a$ (Méléder et al. 2003; Combe et al. 2005), and moisture content (Ben-dor et al. 2002; Adam 2009) in sediments. In the field, good results have been obtained to estimate chlorophyll a content (Méléder et al. 2003; Carrère et al. 2004; Combe et al. 2005; Murphy et al. 2005; Adam 2009) and moderate results to quantify mud (Kooistra et al. 2003; Rainey et al. 2003; Lagacherie et al. 2008) and moisture (Ben-dor et al. 2002; Adam 2009) content.

Few studies used remote sensing data to predict distribution of macrobenthos on an intertidal flat (Yates et al. 1993; van der Wal et al. 2008). However, the effect of bioturbation on the remotely sensed signal and, hence, the potential of remote sensing to detect bioturbation have not been investigated. Nevertheless, bioturbation is recognized as one of the major processes that influence the structure and function of sediment environments (Lohrer et al. 2004; Meysman et al. 2006). Sediment reworking results from various activities and strongly affects the physical, chemical, and biological characteristics of marine sediments (Rhoads 1974; Aller 1982; Hall 1994; Jones et al. 1994; Rowden et al. 1998). As such, bioturbation could potentially influence remote sensing analyses through changing sediment properties.

The mud shrimp, Corophium volutator (Crustacea, Amphipoda), is an abundant deposit and/or filter feeding species in intertidal mudflats where it lives in U-shaped burrows in the upper $5 \mathrm{~cm}$ of the sediment (Meadows and Reid 1966). Population densities frequently reach $>20,000$ individuals per square meter and, in summer months, densities can locally increase up to 100,000-140,000 individuals per square meter (Gerdol and Hughes 1994a). The high population densities make $C$. volutator a critical species in many mudflat ecosystems where it is a significant prey of migratory shore birds and juvenile flounder (Murdoch et al. 1986; Boates et al. 1995). Through its activities, Corophium alters sediment properties by changing the porosity, water content, grain size distribution, and chemistry of the sediment (Jones and Jago 1993; Gerdol and Hughes 1994b; Pelegri and Blackburn 1994; Limia and Raffaelli 1997; Mermillod-Blondin et al. 2004). However, contradicting results are often found and still no consensus on the real effect of Corophium on the physical characteristics of the sediment is reached.

The objectives of the present study were twofold:

1. to examine the physical impact of bioturbation by $C$. volutator on water content and grain size of the sediment with conventional, destructive techniques using microcosms in laboratory conditions, i.e., without any confounding factors such as the presence of microphytobenthos and differences in sediment characteristics,

2. to investigate whether physical changes caused by bioturbation of a macrobenthic species influence the hyperspectral signal.

\section{Material and Methods}

\section{Experimental Setup}

Sediment and C. volutator were collected in October 2007 in the Flemish nature reserve "IJzermonding," a mudflatsaltmarsh area in Nieuwpoort (Belgium, $51^{\circ} 08^{\prime} \mathrm{N}, 2^{\circ} 44^{\prime} \mathrm{E}$ ). The sediment was defaunated by three cycles of $24 \mathrm{~h}$ freezing-24 $\mathrm{h}$ thawing. Grain size analysis (Malvern Mastersizer 2000 laser diffraction) showed that freezingthawing did not alter median grain size ( $t$ test, $p=0.48)$. To reduce natural heterogeneity and to obtain equal starting conditions, the sediment was homogenized by thorough mixing before use. Sediment microcosms were established by transferring the homogenized sediment into PVC cores (15 cm deep and $8 \mathrm{~cm}$ internal diameter) to a depth of $10 \mathrm{~cm}$. Fifteen cores were placed in an aquarium $(0.8 \times$ $0.8 \mathrm{~m})$ in a temperature-controlled climate room $\left(16 \pm 1^{\circ} \mathrm{C}\right)$ with a 12:12-h light/dark regime and subjected to a simulated tidal regime, resembling the natural tidal conditions (i.e., $3 \mathrm{~h}$ of submersion and $9 \mathrm{~h}$ of emersion, salinity= 32 psu). Three days after microcosm preparation, $C$. volutator was added to the PVC cores in different densities. Three treatments were set up (five replicates per treatment): (1) no Corophium, i.e., control (C), (2) 25 Corophium, i.e., low density (5,000 individuals per square meter; LD), and (3) 100 Corophium, i.e., high density (20,000 individuals per square meter; HD). All treatments were placed randomly in the aquarium during 16 days. On day 16, hyperspectral measurements of the sediment surface were performed $3 \mathrm{~h}$ after emersion. Immediately thereafter, the surface sediment was frozen with liquid nitrogen $( \pm 1 \mathrm{~cm}$ deep), based on the contact coring technique pioneered by

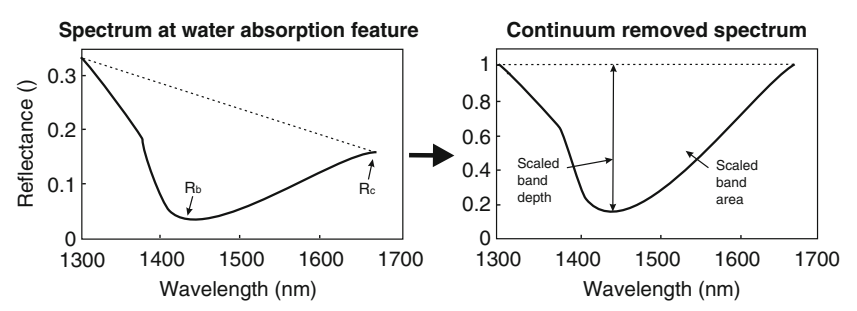

Fig. 1 Measures that quantify absorption features. $R_{\mathrm{b}}$ is the reflectance at maximum absorption, $R_{\mathrm{c}}$ is the reflectance out of absorption feature. Example for the water absorption feature at $1,450 \mathrm{~nm}$ 
Wiltshire et al. (1997). This technique allows for undisturbed surface samples and avoids changes in water content by draining of the pore water. Afterwards, the upper $0.5 \mathrm{~cm}$ of the core was used to determine water content and grain size in the surface layer.

Hyperspectral and Physical Measurements

Spectral Reflectance Measurements Hyperspectral measurements were acquired with the Analytical Spectral Device (ASD) spectrometer (FieldSpec ${ }^{\circledR}$ Pro FR, Analytical Spectral Devices Inc., Boulder, CO, USA), recording the reflectance from 350 to $2,500 \mathrm{~nm}$, i.e., in the visible (VIS), near-infrared (NIR), and shortwave-infrared (SWIR) region of the spectrum. The spectral resolution is $3 \mathrm{~nm}$ for the $350-1,000 \mathrm{~nm}$ region and $10 \mathrm{~nm}$ for the 1,000 $2,500 \mathrm{~nm}$ region. Spectral reflectance measurements were acquired at $50 \mathrm{~cm}$ height, nadir looking with a field of view of $1^{\circ}$, so that a small area of $0.6 \mathrm{~cm}^{2}$ was sampled. The reflectance was measured at four positions in each microcosm on the sediment surface to include spatial heterogeneity. Black cloths, which absorb more than $95 \%$ of the light, were hung around the experimental setup and put on the table to avoid diffuse light entering the sensor. The light source was a tungsten halogen 50-W OSRAM lamp and calibration was performed every 10 min using a Spectralon ${ }^{\circledR}$ panel $(0.30 \times 0.30 \mathrm{~m}$, Labsphere, North Sutton, USA), which has a quasi-Lambertian reflectance higher than $98 \%$ over a range from 400 to $1,500 \mathrm{~nm}$ and higher than $93 \%$ from 1,500 to $2,500 \mathrm{~nm}$. Hence, the Spectralon ${ }^{\circledR}$ panel is characterized by a reflectance factor for each wavelength. The relative reflectance from the sediment (radiant exitance from the sediment/radiant exitance from the Spectralon ${ }^{\circledR}$ panel) was multiplied by the Spectralon ${ }^{\circledR}$ reflectance factors to obtain absolute reflectance. In laboratory conditions, the instrument and the light source are stable enough for calibration to be performed with a 10min time interval, since $10 \mathrm{~min}$ after the calibration, the reflectance of the Spectralon ${ }^{\circledR}$ panel was almost equal to $100 \%$, except for small deviations situated at the extreme upper and lower ends of the spectrum.

In order to avoid measurements with an incorrect position of the sample under the ASD, causing reflectance from the PVC cores, a quality procedure based on the overall brightness of the spectrum was performed. One spectrum of the high-density treatment had to be removed because the difference in the visible light between this spectrum and the mean of the other high-density spectra was very large (more than five times the standard deviation of the correctly measured high-density spectra).

Water Content Frozen sediment from 0 to $0.5 \mathrm{~cm}$ depth is weighed after removal of the animals to determine wet weight, subsequently freeze-dried for $12 \mathrm{~h}$, and weighed again. Water content was calculated as follows:

Water content $(\%)$

$$
=\frac{\text { Wet sample weight }(\mathrm{g})-\text { Dry sample weight }(\mathrm{g})}{\text { Wet sample weight }(\mathrm{g})} \times 100 \text {. }
$$

Grain Size Grain size analysis was carried out on the freezedried samples $(8 \mathrm{~cm} \varnothing)$ after determination of the water content. Grain size distribution (according to the Wentworth scale) and mean grain size (in micrometers) were determined using a Malvern Mastersizer 2000 laser diffraction, capable of detecting the $0.02-\mu \mathrm{m}$ to $2-\mathrm{mm}$ grain size range.

\section{Absorption Features}

Absorption can be quantified by (1) the ratio between minimal reflectance in the absorption feature and reflectance outside the absorption feature: $R_{\mathrm{b}} / R_{\mathrm{c}}\left(R_{\mathrm{b}}\right.$ is the reflectance at maximum absorption, $R_{\mathrm{c}}$ is the reflectance out of absorption feature), (2) the scaled band depth after continuum removal, and (3) the scaled band area of the absorption feature after continuum removal (Fig. 1). Continuum removal is a normalization technique in order to compare absorption features from a common baseline. This continuum consists of straight-line segments that connect local spectra maxima. It is then removed by dividing it into the actual spectrum (Clark and Roush 1984). The continuum is calculated preferably between the local maxima of the absorption feature of interest. If there is no local maximum, the shoulder of the dip or a predefined wavelength is considered for continuum removal.

Specifically, we used the absorption dips at 1,450 and 2,206 $\mathrm{nm}$ as assessors for water and clay content, respectively. A laboratory spectrum for dry fine sand with clay shows absorption features of clay at around 1,420, 1,950, and 2,206 nm (Fig. 2; Adam et al. 2008) where the latter is caused by $\mathrm{Al}-\mathrm{OH}$ bonds in the clay
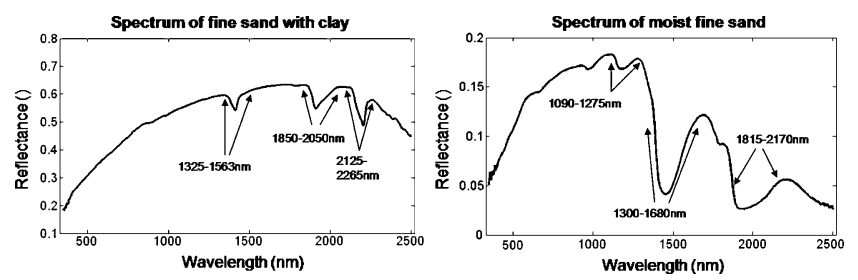

Fig. 2 Spectrum of dry fine sand with clay ( $66 \%$ by weight; left) and of moist fine sand $(\mathrm{RMC}=27 \%$; right; from Adam et al. 2008) 

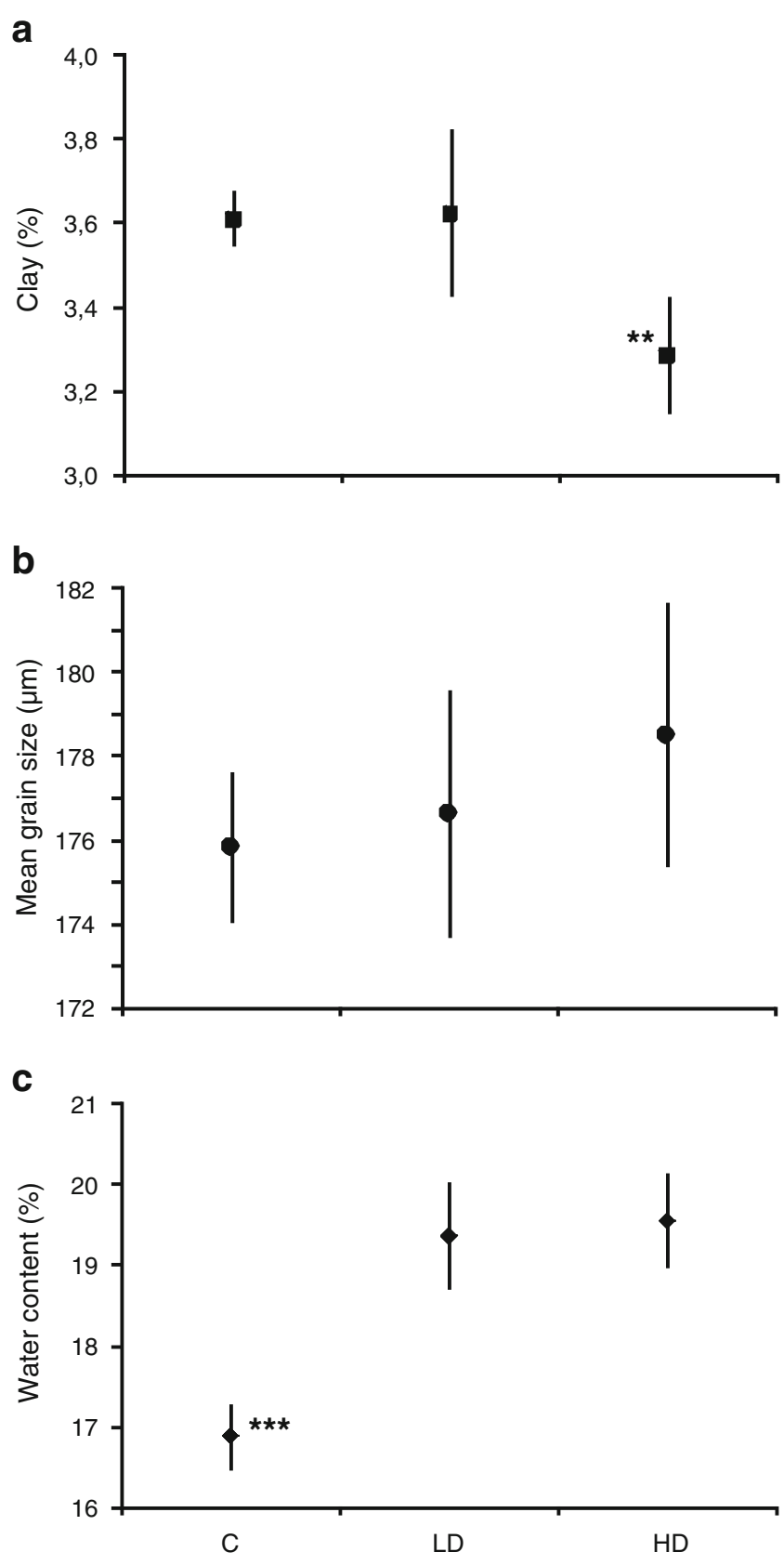

Fig. 3 a Average percentage of clay, $\mathbf{b}$ average mean grain size, and $\mathbf{c}$ average water content (in percent) for the different treatments $(n=5 \pm$ SD; $C$ control, $L D$ low density, $H D$ high density); $* * p<0.01$ and $* * * p$ $<0.001$, significance levels of Tukey's post hoc mineral (Yang et al. 2000). Absorption at around 1,420 and $1,950 \mathrm{~nm}$ is also due to clay molecular water absorbing light (Hunt 1977; Yang et al. 2000). Therefore, the best assessor for clay content is the absorption dip at $2,206 \mathrm{~nm}$.

The spectrum of moist fine sand shows water absorption features at 970, 1,190, 1,450, and 1,950 nm (Fig. 2; Adam et al. 2008). The first two disappear when the sediment is drier, and the latter becomes saturated at relatively low moisture contents (measurements by S. Adam). Furthermore, the best prediction potential of relative moisture content in laboratory conditions was obtained using the scaled band area of the water absorption feature at $1,450 \mathrm{~nm}$ (measurements by S. Adam). For these reasons, the absorption at $1,450 \mathrm{~nm}$ was considered in the further analysis.

\section{Data Analysis}

Differences in density treatments were tested using oneway analysis of variance (ANOVA). Percentage data (clay, water content) were arcsine-square root transformed; reflectance $(\times 10)$ and mean grain size data were $\log$ transformed to meet assumptions of normality (Shapiro Wilks' test) and homogeneity of variances (Cochran and Bartlett tests). Whenever appropriate, a Tukey's post hoc test was used to assess differences between treatments. Furthermore, to investigate relationships between density, physical characteristics, and spectral measurements, Pearson's product-moment correlations were performed.

\section{Results}

\section{Physical Characteristics}

The high-density treatment (HD) had a significantly ( $p<$ 0.01 , Tukey's post hoc) lower percentage clay (mean $\pm \mathrm{SD}$, $3.3 \pm 0.1 \%)$ in the upper layer than the low-density treatment $(\mathrm{LD} ; 3.6 \pm 0.2 \%)$ and the control treatment $(\mathrm{C}$; $3.6 \pm 0.06 \%$; Fig. 3a). Furthermore, we found a negative correlation between density and clay percentage (Pearson's

Table 1 One-way ANOVA table to determine significant differences for the different physical characteristics (clay percentage, mean grain size, and water content) between the different treatments

\begin{tabular}{lrllllllll}
\hline & $d f$ & Clay \% MS & Clay \% F & $p$ value & Mean MS & Mean F & $p$ value & Water \% MS & Water \% MS \\
\hline Treatment & 2 & 0.0001 & 8.9 & 0.004 & 0.00005 & 1 & 0.4 & 0.002 & 37.4 \\
Error & 12 & 0.00002 & & & 0.00004 & & & 0.00005 & $<0.001$ \\
\hline
\end{tabular}

Clay percentage and water content were arcsine-square root transformed, median grain size was log transformed. Significant $p$ levels are italicized 
Table 2 One-way ANOVA table to determine significant differences for the hyperspectral measurements (reflectance at 545 and $630 \mathrm{~nm}$ and scaled band area $1,450 \mathrm{~nm}$ ) between the different treatments

\begin{tabular}{lrllllllll}
\hline & $d f$ & $\begin{array}{l}\text { Refl 545 } \\
\text { MS }\end{array}$ & Refl 545 F & $p$ value & $\begin{array}{l}\text { Refl 630 } \\
\text { MS }\end{array}$ & Refl 630 F & $p$ value & $\begin{array}{l}\text { Area 1450 } \\
\text { MS }\end{array}$ & $\begin{array}{l}\text { Area 1450 } \\
\text { MS }\end{array}$ \\
\hline $\begin{array}{l}\text { Treatment } \\
\text { Error }\end{array}$ & 2 & $\begin{array}{l}0.01 \\
0.0009\end{array}$ & 15.9 & $<0.001$ & $\begin{array}{l}0.01 \\
0.0007\end{array}$ & 16.8 & $<0.001$ & 0.02 & 21 \\
\end{tabular}

All variables were $\log (\times 10)$ transformed. Significant $p$ levels are italicized

$r=-0.75, p=0.0014)$. Mean grain size of $\mathrm{HD}(179 \pm 3 \mu \mathrm{m})$ was larger as well $(\mathrm{LD}=177 \pm 3 \mu \mathrm{m}, \mathrm{C}=176 \pm 2 \mu \mathrm{m}$; Fig. 3b). However, no significant differences in mean grain sizes were found.

Water content increased significantly when Corophium was present, both for LD $(19 \pm 0.7 \%)$ and HD $(20 \pm 0.6 \%)$, compared to C $(17 \pm 0.4 \%$; Fig. 3c, Table 1$)$. No difference however, was found between LD and HD (Tukey's post hoc, $p>0.05$ ). Water content correlated positively with density with Pearson's $r=0.68(p=0.005)$.

\section{Hyperspectral Measurements}

The reflectance in the visible region of the spectrum differed significantly between the density treatments, as shown in Table 2 for the reflectance at 545 and $630 \mathrm{~nm}$ and in Fig. 4.

The continuum removed spectra at the absorption dip of water at 1,450 nm (Fig. 5) show that the dips are maximum for the treatments with Corophium and minimum for C. As expected, the scaled band area of the water absorption feature at $1,450 \mathrm{~nm}$ was positively correlated with water content (Pearson's $r=0.8, p=0.0006$ ). Differences between the three treatments (Table 2) were significant for the scaled band area at $1,450 \mathrm{~nm}$ where $\mathrm{C}$ differed significantly from LD and HD (Tukey's post hoc, respectively, $p=0.0003$ and $p=0.005$; Fig. 6).

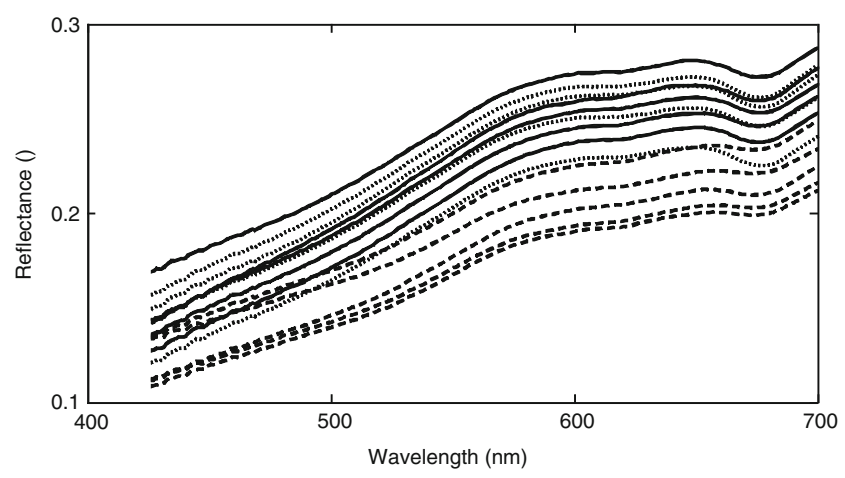

Fig. 4 Reflectance in the visible region of the spectrum of sediment without (dashed line) C. volutator, with 5,000 individuals per square meter (solid line), and with 20,000 individuals per square meter (dotted line)
For the clay absorption feature at 2,206 nm, scaled band area was zero for all treatments. The absence of a clay absorption feature was due to the absorption by water and the high signal noise in this region of the spectrum.

\section{Discussion}

Physical Impact of Corophium volutator

Our experiment showed that whenever Corophium was present, both in low and high density, changes in water content of the surface sediment were visible, i.e., water content of the top half centimeter increased. No difference was detected between the two density treatments, but the difference between control sediment and sediment with Corophium was significant. Gerdol and Hughes (1994b) found results consistent with our study, while other studies found opposite results (Meadows and Tait 1989) or no influence of Corophium on water content (Grant and Daborn 1994; Limia and Raffaelli 1997; de Deckere et al. 2000). In our study, however, no biofilm was present (unlike in the above-mentioned studies) to be able to focus on the effect caused solely by $C$. volutator. Thus, in our experiment, complexity was reduced by excluding confounding factors such as the presence of a biofilm, since it is proven more than once that the presence of a biofilm increases water content of the surface sediment (Defew et

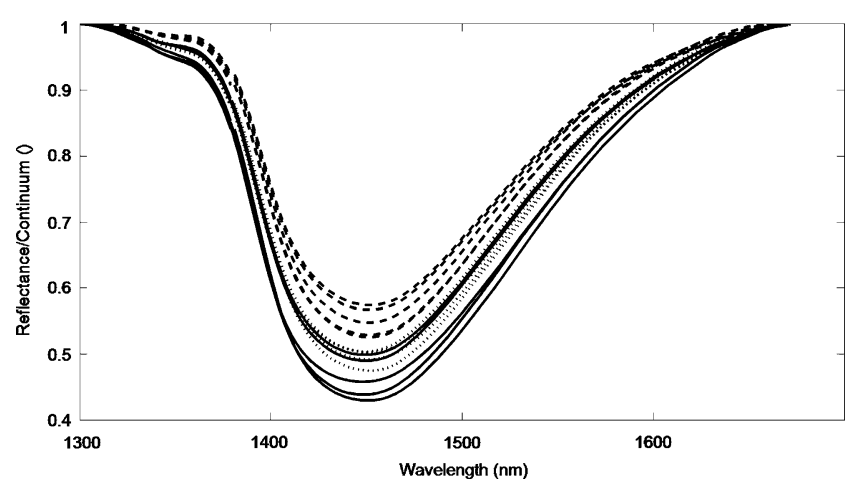

Fig. 5 Continuum removed spectra at the water absorption feature at $1,450 \mathrm{~nm}$ for the control (dashed line), low-density (solid line), and high-density (dotted line) treatments 


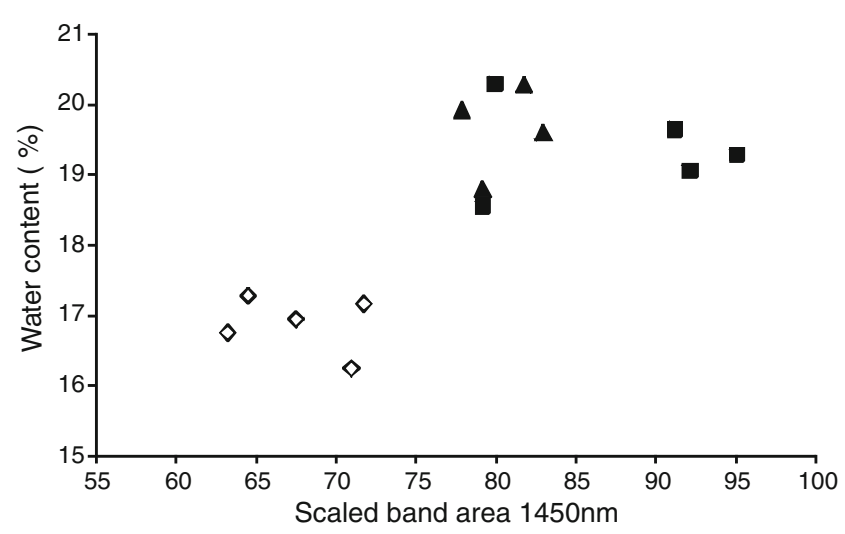

Fig. 6 Scatter plot of scaled band area 1,450 nm versus water content (in percent) for the different treatments (white diamond control, black square low density, black triangle high density)

al. 2003; Orvain et al. 2003). The presence of a biofilm might explain why in some studies no difference was found between a control with biofilm and treatments with Corophium. In a control treatment, the biofilm retains water, which increases water content. On the other hand, in the Corophium treatment, the biofilm is grazed upon by Corophium (Gerdol and Hughes 1994a), so it does not retain water, but then again Corophium influences the water content due to bioturbation. This indicates that the impact of the presence of a biofilm and the presence of Corophium on the water content counterbalance each other and no significant effects are found. On the other hand, the absence of a biofilm could possibly affect bioturbation rates, since food is absent. As is generally the case for infauna (Rhoads 1974), the presence of $C$. volutator led probably to an increase in pore space. In addition, the saturation on emersion increased, caused by retention of water due to the secretion of burrow linings (Meadows et al. 1990; Gerdol and Hughes 1994b), and this caused an increase in water content in the sole presence of Corophium. It should be considered, however, that the drainage in the laboratory was different from natural conditions, since groundwater level was not able to drain as in natural conditions, and there was also no drying due to sun or wind. Nevertheless, conditions were constant and standard for all treatments, so we can expect that observations made were consistent, but the water content for this top layer was higher than in natural conditions, both for control and density treatments.

Another physical change visible in the top half centimeter due to bioturbation of $C$. volutator was the increase in mean grain size at high density. This increase was mainly caused by the significant loss of the clay fraction in the top layer. C. volutator is known to actively resuspend particles during feeding and burrowing (de Deckere et al. 2000), and moreover, Corophium was observed to flush its burrows immediately after submersion (De Backer et al. 2006). Both activities probably contribute to the loss of the finest particles, since these smallest, and thus lightest, particles resuspend easier and get washed away with the tides, while the heavier and biggest particles remain on the sediment surface. Only at high density, the decrease in clay percentage was significant indicating that only at high densities Corophium considerably contributes to the sediment grain size distribution. This result is consistent with a previous study that quantified bioturbation effects of Corophium using luminophores (De Backer et al., unpublished data). In that study, the density of Corophium was found an important factor affecting the magnitude of bioturbation, and mainly high densities of $C$. volutator significantly contributed to sediment mixing (De Backer et al., unpublished data).

\section{Physical Changes Influencing Remote Sensing}

Results showed that the changes in water content due to bioturbation of $C$. volutator affected the spectral reflectance. The higher percentage of water content in the treatments with Corophium increased the reflectance of the visible light $(545$ and $630 \mathrm{~nm})$. At low sediment moisture conditions, the sediment becomes darker (decrease in reflectance) with increasing sediment moisture, but this relation is reversed at a certain water content which is dependent on the soil hydrodynamic properties (Weidong et al. 2002). This means that, for the high water contents of our sediment samples, the reflectance increases for higher water content and the change in reflectance is the highest in the visible light for sediment with high water content (Weidong et al. 2002). This increase in reflectance can be explained by a water film covering all the sediment particles and changing the scattering processes (Neema et al. 1987). The difference in water content between control and density treatments was also noted in an increase in light absorption at around $1,450 \mathrm{~nm}$ by water. The light absorption was quantified by the scaled band area of the water absorption feature, which is a better measure than the scaled band depth to quantify water content because, at these high water contents, the absorption dip not only becomes deeper, but also wider (Adam et al. 2008). No differences in water absorption between density treatments were measured, which was consistent with the analyzed water contents.

The small but significant decrease in clay content on the sediment surface for the high-density treatment did not influence the hyperspectral measurements. The clay absorption dip at 2,206 $\mathrm{nm}$ has been used in laboratory conditions in dry soils to assess differences in clay content (Lagacherie et al. 2008; Adam 2009) with a root mean square error of prediction between 3.5 and 5.8 wt.\% (Lagacherie et al. 2008) and between 1.3 and 1.4 wt.\% 
(Adam 2009). Since the differences in clay content for the control, low-density, and high-density treatments were smaller than these error values, the clay absorption dip was not successful to detect changes in clay content between the treatments. Furthermore, the absorption dip was not visible in the spectra, since clay absorption degrades with increasing moisture content due to water absorbing light in this region of the spectrum (Adam et al. 2008, Adam 2009). In general, quantification of clay content in moist sediments using hyperspectral remote sensing is very difficult (Rainey et al. 2003; van der Wal and Herman 2007; Adam 2009).

\section{Some Considerations and Conclusions}

Our laboratory results showed that the bioturbation activity of a species can influence the hyperspectral signal. $C$. volutator was used to test this objective, and we observed an increase in water content in the presence of Corophium. This increase could be measured hyperspectrally through an increased reflectance in the visible light and an increase of scaled band area of the water absorption feature at $1,450 \mathrm{~nm}$. With conventional destructive sampling, no difference was found between the low-density and highdensity treatment, and this was consistently measured hyperspectrally. However, generalization to other macrobenthic species should be done with care because each species alters physical, chemical, and biological characteristics of marine sediments in a different way (Rhoads 1974; Aller 1982; Meadows and Meadows 1991; Hall 1994; Rowden et al. 1998). These macrobenthos-mediated effects on sediment processes are strongly influenced by speciesspecific life modes (Mermillod-Blondin et al. 2005). Nevertheless, the application of remote sensing in the laboratory seems promising to address the impact of bioturbation in terms of water content. For Corophium, there was no difference in water content between different densities, but the hyperspectral results indicate that, if for other species differences in water content would exist and also be large enough and consistent, hyperspectral laboratory measurements should be able to detect them.

A decrease in clay content was measured at high densities of Corophium, probably due to resuspension and wash out of this finest fraction by bioturbation. This decrease was too small to be detectable by remote sensing.

Airborne spectral measurements have been used to determine in situ sediment properties in an undisturbed manner (Ben-dor et al. 2002; Carrère 2003; Deronde et al. 2006; Lagacherie et al. 2008). But even though hyperspectral airborne sensors, such as HyMap, contain the spectral detail necessary to quantify water absorption, it is not possible to extrapolate the obtained results from this study to field conditions because we used a simplified ecosystem in which only one mechanism was studied. Yet in natural intertidal sediments, these comparatively simple relationships disappear, being replaced with complex interactions between the biological and physical components which create considerable temporal and spatial variability, resulting in apparently site-specific responses in the properties of sediment (Riethmüller et al. 1998; Defew et al. 2002; Chapman and Tolhurst 2004). Nevertheless, this study showed that bioturbation can significantly influence remote sensing analyses. Thus, remote sensing for the assessment of environmental variables needs to take into account the potential impact of bioturbation activities because they significantly affect reflectance properties.

Furthermore, this study proved the usefulness of the application of remote sensing to study biologically induced changes in sediment properties in a nondestructive manner. Future laboratory experiments studying animal-sediment relationships can gain advantage in using hyperspectral measurements. Changes in physical surface properties can be measured without disturbing the sediment surface and it is possible to follow up biologically reworked sediments in time. This can, especially, open new perspectives for longterm experiments concerning the role of bioturbation on sedimentary processes.

Acknowledgements The first author acknowledges a research assistant grant from Ghent University (UGent). The second author was financed through the FWO-Vlaanderen (Research FoundationFlanders) project KISS (contract no. G.0480.05) and the Belgian Federal Science Policy in the frame of the STEREO program - project 109 (Algased). This research contributes to the EU Network of Excellence MarBEF (contract no. GOCE-CT-2003-505446) and the Ghent University BBSea project (contract no. GOA 01G00705). Furthermore, we thank the Flemish authorities (ANB) for the permission to sample in the Nature Reserve "IJzermonding." Two anonymous reviewers provided many useful suggestions and recommendations to improve the final manuscript.

\section{References}

Adam, S. 2009. Bio-physical characterization of sediment stability indicators for mudflats using remote sensing. Ph.D. thesis, Katholieke Universiteit Leuven, $162 \mathrm{p}+$ appendices.

Adam, S., I. Vitse, C. Johannsen, and J. Monbaliu. 2006. Sediment type unsupervised classification of the Molenplaat, Westerschelde Estuary, The Netherlands. EARSeL eProceedings 5: 146-160.

Adam, S., J. Monbaliu, and E. Toorman. 2008. Quantification of biophysical intertidal sediment properties using hyperspectral laboratory and in situ measurements. In 28th EARSeL Symposium and Workshops, Remote Sensing for a Changing Europe, 2-7 June, Istanbul.

Aller, R.C. 1982. The effects of macrobenthos on chemical properties of marine sediment and overlying water. In Animal-sediment relations, ed. P.L. Mc Call and M.J.S. Tevest, 53-102. New York: Plenum. 
Ben-dor, E., K. Patkin, A. Banin, and A. Karnieli. 2002. Mapping of several soil properties using DAIS-7915 hyperspectral scanner data - a case study over clayey soils in Israel. International Journal of Remote Sensing 23: 1043-1062.

Boates, J.S., M. Forbes, M. Zinck, and N. McNeil. 1995. Male amphipods Corophium volutator (Pallas) show flexible behaviour in relation to risk of predation by sandpipers. Ecoscience 2(2): $123-128$

Carrère, V. 2003. Mapping microphytobenthos in the intertidal zone of Northern France using high spectral resolution field and airborne data. Presented at the 3rd EARSeL Workshop on Imaging Spectroscopy, Herrsching, 13-16 May.

Carrère, V., N. Spilmont, and D. Davouli. 2004. Comparison of simple techniques for estimating chlorophyll $a$ concentration in the intertidal zone using high spectral-resolution field-spectrometer data. Marine Ecology Progress Series 274: 31-40.

Chapman, M.G. and T.J. Tolhurst. 2004. The relationship between invertebrate assemblages and bio-dependent properties of sediment in urbanized temperate mangrove forests. Journal of Experimental Marine Biology and Ecology 304: 51-73.

Clark, R.N. and T. Roush. 1984. Reflectance spectroscopy: quantitative analysis techniques for remote sensing applications. Journal of Geophysical Research 89: 6329-6340.

Combe, J.-P., P. Launeau, V. Carrère, D. Despan, V. Méléder, L. Barillé, and C. Sotin. 2005. Mapping microphytobenthos biomass by non-linear inversion of visible-infrared hyperspectral images. Remote Sensing of Environment 98: 371-387.

De Backer, A., E. Van Ael, M. Vincx, and S. Degraer. 2006. The secret life of Corophium volutator, an important bioturbator on mudflats. In VLIZ Young Scientists' Day, Brugge, Belgium, 31 March 2006: Book of Abstracts. VLIZ Special Publication 30, ed. J. Mees, and J. Seys, 27 Oostende: VLIZ (Vlaams Instituut voor de Zee).

de Deckere, E.M.G.T., J. van de Koppel, and C.H.R. Heip. 2000. The influence of Corophium volutator abundance on resuspension. Hydrobiologia 426: 37-42.

Defew, E.C., T.J. Tolhurst, and D.M. Paterson. 2002. Site-specific features influence sediment stability of intertidal flats. Hydrology and Earth System Sciences 6(5): 971-982.

Defew, E.C., T.J. Tolhurst, D.M. Paterson, and S.E. Hagerthey. 2003. Can the stability of intertidal sediments be predicted from proxy parameters? An in situ investigation, 61-70. Leamington Spa: Estuarine and Coastal Sciences Association.

Deronde, B., P. Kempeneers, and R.M. Forster. 2006. Imaging spectroscopy as a tool to study sediment characteristics on a tidal sandbank in the Westerschelde. Estuarine, Coastal and Shelf Science 69: 580-590.

Gerdol, V. and R.G. Hughes. 1994a. Feeding behaviour and diet of Corophium volutator in an estuary in southeastern England. Marine Ecology Progress Series 114: 103-108.

Gerdol, V. and R.G. Hughes. 1994b. Effect of Corophium volutator on the abundance of benthic diatoms, bacteria and sediment stability in two estuaries in southeastern England. Marine Ecology Progress Series 114: 109-115.

Grant, J. and G. Daborn. 1994. The effects of bioturbation on sediment transport on an intertidal mudflat. Netherlands Journal of Sea Research 32(1): 63-72.

Hall, S.J. 1994. Physical disturbance and marine benthic communities: life in unconsolidated sediments. Oceanography and Marine Biology. Annual Review 32: 179-219.

Hunt, G.R. 1977. Spectral signatures of particulate minerals in the visible and near-infrared. Journal of Geophysical Research 95: 12653-12680.

Jones, S.E. and C.F. Jago. 1993. In situ assessment of modification of sediment properties by burrowing invertebrates. Marine Biology 115: 133-142.
Jones, C.G., J.H. Lawton, and M. Shachak. 1994. Organisms as ecosystem engineers. Oikos 69: 373-386.

Kooistra, L., J. Wanders, G.F. Epema, R.S.E.W. Leuven, R. Wehrens, and L.M.C. Buydens. 2003. The potential of field spectroscopy for the assessment of sediment properties in river floodplains. Analytica Chimica Acta 484: 189-200.

Lagacherie, P., F. Baret, J.-B. Feret, J. Madeira Netto, and J.M. Robbez-Masson. 2008. Estimation of soil clay and calcium carbonate using laboratory, field and airborne hyperspectral measurements. Remote Sensing of Environment 112: 825-835.

Lillesand, T.M. and R.W. Kiefer. 2000. Remote sensing and image interpretation, vol. 4. New York: Wiley.

Limia, J. and D. Raffaelli. 1997. The effects of burrowing by the amphipod Corophium volutator on the ecology of intertidal sediments. Journal of the Marine Biological Association of the UK 77: 409-423.

Lohrer, A.M., S.F. Thrush, and M.M. Gibbs. 2004. Bioturbators enhance ecosystem function through complex biogeochemical interactions. Nature 43: 1092-1095.

Meadows, P.S. and A. Meadows. 1991. The geotechnical and geochemical implications of bioturbation in marine sedimentary ecosystems. Symposia of the Zoological Society of London 63: $157-181$.

Meadows, P.S. and A. Reid. 1966. The behaviour of Corophium volutator (Crustacea: Amphipoda). Journal of Zoology 150: 387399.

Meadows, P.S. and J. Tait. 1989. Modification of sediment permeability and shear strength by two burrowing invertebrates. Marine Biology 101: 75-82.

Meadows, P.S., J. Tait, and S.A. Hussain. 1990. Effects of estuarine infauna on sediment stability and particle sedimentation. Hydrobiologia 190: 263-266.

Méléder, V., L. Barillé, P. Launeau, V. Carrère, and Y. Rincé. 2003. Spectrometric constraint in analysis of benthic diatom biomass using monospecific cultures. Remote Sensing of Environment 88: 386-400.

Mermillod-Blondin, F., R. Rosenberg, F. Francois-Carcaillet, K. Norling, and L. Mauclaire. 2004. Influence of bioturbation by three benthic infaunal species on microbial communities and biogeochemical processes in marine sediment. Aquatic Microbial Ecology 36(3): 271-284.

Mermillod-Blondin, F., F. François-Carcaillet, and R. Rosenberg. 2005. Biodiversity of benthic invertebrates and organic matter processing in shallow marine sediments: an experimental study. Journal of Experimental Marine Biology and Ecology 315(2): 187-209.

Meysman, F.J., J.J. Middelburg, and C.H. Heip. 2006. Bioturbation: a fresh look at Darwin's last idea. Trends in Ecology and Evolution 21(12): 688-695.

Murdoch, M.H., F. Bärlocher, and M.L. Laltoo. 1986. Population dynamics and nutrition of Corophium volutator (Pallas) in the Cumberland Basin (Bay of Fundy). Journal of Experimental Marine Biology and Ecology 103: 235-249.

Murphy, R.J., T.J. Tolhurst, M.G. Chapman, and A.J. Underwood. 2005. Estimation of surface chlorophyll $a$ on an emersed mudflat using field spectrometry: accuracy of ratios and derivative-based approaches. International Journal of Remote Sensing 26: 18351859.

Neema, D.L., A. Shah, and A.N. Patel. 1987. A statistical optical model for light reflection and penetration through sand. International Journal of Remote Sensing 8(8): 1209-1217.

Pelegri, S.P. and T.H. Blackburn. 1994. Bioturbation effects of the amphipod Corophium volutator on microbial nitrogen transformations in marine sediments. Marine Biology 121: 253-258.

Orvain, F., R. Galois, C. Barnard, A. Sylvestre, G. Blanchard, and P. G. Sauriau. 2003. Carbohydrate production in relation to micro- 
phytobenthic biofilm development: an integrated approach in a tidal mesocosm. Microbial Ecology 45(3): 237-251.

Rainey, M.P., A.N. Tyler, D.J. Gilvear, R.G. Bryant, and P. McDonald. 2003. Mapping intertidal estuarine grain size distributions through airborne remote sensing. Remote Sensing of Environment 86: $480-490$.

Rhoads, D.C. 1974. Organism-sediment relations on the muddy sea floor. Oceanography and Marine Biology. Annual Review 12: 263-300.

Riethmüller, R., J.H.M. Hakvoort, M. Heineke, K. Heymann, H. Kühl, and G. Witte. 1998. Relating erosion thresholds to tidal flat surface colour. In Sedimentary processes in the intertidal zone, eds. K.S. Black, D.M. Paterson, and A. Cramp. Journal of the Geological Society of London (Special Issue) 139: 283-293.

Rowden, A.A., C.F. Jago, and S.E. Jones. 1998. Influence of benthic macrofauna on the geotechnical and geophysical properties of surficial sediment, North Sea. Continental Shelf Research 18: 1347-1363.

Thomson, A.G., J.A. Eastwood, M.G. Yates, R.M. Fuller, R.A. Wadsworth, and R. Cox. 1998. Airborne remote sensing of intertidal biotopes: BIOTA I. Marine Pollution Bulletin 37: 164172.

van der Wal, D. and P.M.J. Herman. 2007. Regression-based synergy of optical, shortwave infrared and microwave remote sensing for monitoring the grain-size of intertidal sediments. Remote Sensing of Environment 111: 89-106.

van der Wal, D., P.M.J. Herman, R.M. Forster, T. Ysebaert, F. Rossi, E. Knaeps, Y.M.G. Plancke, and S.J. Ides. 2008. Distribution and dynamics of intertidal macrobenthos predicted from remote sensing: response to microphytobenthos and environment. $M a$ rine Ecology Progress Series 367: 57-72.

Weidong, L., F. Baret, G. Xingfa, T. Qingxi, Z. Lanfen, and Z. Bing. 2002. Relating soil surface moisture to reflectance. Remote Sensing of Environment 81: 238-246.

Wiltshire, K.H., S. Harsdorf, B. Smidt, G. Blocker, R. Reuter, and F. Schroeder. 1997. The determination of algal biomass (as chlorophyll) in suspended matter from the Elbe Estuary and the German Bight: a comparison of high-performance liquid chromatography, delayed fluorescence and prompt fluorescence methods. Journal of Experimental Marine Biology and Ecology 222: 113-131.

Yang, K., J.F. Huntington, P.R.L. Browne, and C. Ma. 2000. An infrared spectral reflectance study of hydrothermal alteration minerals from the Te Mihi Sector of the Wairakei Geothermal System, New Zealand. Geothermics 29: 377-392.

Yates, M.G., A.R. Jones, S. McGrorty, and J.D. Goss-Custard. 1993. The use of satellite imagery to determine the distribution of intertidal surface sediments of the Wash, England. Estuarine, Coastal and Shelf Science 36: 333-344. 